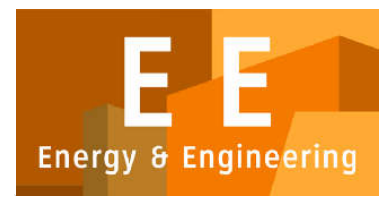

PAPER - OPEN ACCESS

\title{
Penjadwalan Produksi Flowshop Dengan Menggunakan Metode Tabu Search Di PT. Jaya Beton Indonesia
}

\author{
Author : : Andreas Teddy Sirait dan Rosnani Ginting \\ DOI $\quad: 10.32734 /$ ee.v2i3.745 \\ Electronic ISSN $\quad: 2654-704 X$ \\ Print ISSN $\quad: 2654-7031$
}

Volume 2 Issue 3 - 2019 TALENTA Conference Series: Energy \& Engineering (EE)

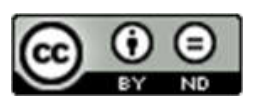

This work is licensed under a Creative Commons Attribution-NoDerivatives 4.0 International License.

Published under licence by TALENTA Publisher, Universitas Sumatera Utara 


\title{
نं

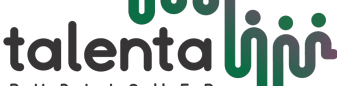 \\ TALENTA Conference Series
}

Available online at https://talentaconfseries.usu.ac.id

\section{Penjadwalan Produksi Flowshop Dengan Menggunakan Metode Tabu Search Di PT. Jaya Beton Indonesia}

\author{
Andreas Teddy Sirait ${ }^{1}$, Rosnani Ginting ${ }^{2}$ \\ ${ }^{1}$ Jl. Martabe III No. 5 Lubuk Pakam, Indonesia \\ ${ }^{2}$ Kampus USU, Jl. Almamater, Padang Bulan, Kota Medan 20155, Indonesia \\ 1 andreasteddy1603@gmail.com, ${ }^{2}$ rosnani_usu@yahoo.co.id
}

\begin{abstract}
Abstrak
Penelitian ini dilakukan di PT. XYZ yang merupakan perusahaan manufaktur yang bergerak dalam bidang pembuatan tiang pancang beton. Sebagai perusahaan yang bersifat make to order, PT. XYZ masih menerapkan aturan First Come First Serve (FCFS) dalam memenuhi pesanan. PT. XYZ dibangun oleh PT. XYZ pada tahun 1978 yang muncul dari aspirasi untuk mengikuti kemajuan perkembangan yang sangat cepat dalam sektor industri dan infrastruktur. Beberapa proyek besar telah disupplai oleh PT. Jaya Beton Indonesia.

Data tahun 2012 menunjukkan terdapat 12 keterlambatan, yang disebabkan pengunaan aturan $F C F S$. Oleh sebab itu dilakukan penjadwalan dengan kriteria minimisasi makespan. Makespan adalah total waktu penyelesaian seluruh job, yang dihitung berdasarkan selisih antara waktu stop job terakhir dengan waktu start job pertama. Melalui pendekatan makespan, diharapkan dapat menekan lama waktu produksi.

Hasil penelitian untuk order bulan Juli 2013 menunjukkan makespan yang dihasilkan pada jadwal perusahaan dengan menggunakan FCFS adalah 815.6 jam dan Algoritma Tabu Search 760,5. Beda Relatif menunjukkan bahwa penghematan makespan yang diperoleh dengan menggunakan Algoritma Tabu Search adalah 7,24 \% dan nilai Efficiency Index sebesar 1,0724. Dapat disimpulkan bahwa Algoritma Tabu Search menghasilkan makespan yang lebih kecil dari pada penjadwalan aktual di perusahaan. Urutan job yang dihasilkan: Job 1 - Job 4 - Job2 -Job 3 - Job 7- Job 6-Job 8- Job 5.
\end{abstract}

Kata kunci: Flowshop Scheduling, Algoritma Tabu Search, Makespan, Tiang Pancang

\begin{abstract}
This research was conducted at PT. XYZ which is a manufacturing company engaged in the manufacture of concrete piles. As a company that is make to order, PT. XYZ still applies the First Come First Serve (FCFS) rule in fulfilling orders. PT. XYZ was built by PT. XYZ in 1978 emerged from aspirations to keep up with the very fast progress in the industrial and infrastructure sectors. Several large projects have been supplied by PT. XYZ.

Data for 2012 shows 12 delays caused by the use of FCFS rules. Therefore, scheduling is done using makespan minimization criteria. Makespan is the total time for completing all jobs, which is calculated based on the difference between the last time the stop job and the first job start time. Through the makespan approach, it is expected to reduce the length of production time.

The results of the study for the order in July 2013 showed that the makespan produced on the company's schedule using FCFS was 815.6 hours and the Tabu Search Algorithm was 760.5. Relative Difference shows that saving makespan obtained using the Tabu Search Algorithm is $7.24 \%$ and the Efficiency Index value is 1.0724 . It can be concluded that the Tabu Search algorithm produces a makespan that is smaller than the actual scheduling in the company. Sequence of jobs produced: Job 1 - Job 4 - Job2 -Job 3 - Job 7- 6-Job Job 8- Job 5.
\end{abstract}

Keywords: Flowshop Scheduling, Algoritma Tabu Search, Makespan, Tiang Pancang

(C) 2019 The Authors. Published by TALENTA Publisher Universitas Sumatera Utara

Selection and peer-review under responsibility of The 3nd National Conference on Industrial Engineering (NCIE)

2019

p-ISSN: 2654-7031, e-ISSN: 2654-704X, DOI: 10.32734/ee.v2i3.745 


\section{Pendahuluan}

Hampir di setiap perusahaan manufaktur pasti memiliki serangkaian proses produksi untuk menghasilkan produk. Proses produksi dapat berjalan dengan baik apabila diikuti dengan pekerja dan fasilitas yang sesuai dengan kebutuhan perusahaan. Mengefisienkan pekerja merupakan salah satu hal yang sangat berpengaruh terhadap peningkatan produktivitas.[1]

Penjadwalan merupakan kegiatan mengalokasikan sumber daya yang terbatas untuk menyelesaikan sejumlah pekerjaan. Keterbatasan sumber daya yang dimiliki menimbulkan proses penjadwalan sehingga diperlukan adanya pengaturan sumber-sumber daya tersebut secara efisien. Unit-unit produksi (resources) dapat dimanfaatkan secara optimum dengan dilakukan pengurutan pekerjaan ini. Berbagai model penjadwalan telah dikembangkan untuk mengatasi persoalan penjadwalan tersebut [2].

PT. XYZ merupakan perusahaan pembuatan beton yang menggunakan sistem flow shop dan permintaannya bersifat make to order. Perusahaan harus dapat menjaga kepercayaan konsumennya agar tetap melakukan pemesanan kepada perusahaan. Salah satu faktor yang harus diperhatikan untuk mempertahankan konsumen adalah melakukan pengiriman produk tepat waktu. Apabila perusahaan terlambat dalam mengirimkan produk ke konsumen maka perusahaan akan dikenakan penalti dan sebaliknya jadwal pengiriman yang terlalu cepat bisa mengakibatkan kerugian bagi konsumen seperti biaya penyimpanan terhadap produk tersebut atau resiko kerusakan akibat penyimpanan. Sistem penjadwalan PT. XYZ saat ini menggunakan aturan First Come First Serve (FCFS). Pada aturan FCFS, tidak mempersoalkan singkat atau lamanya waktu proses. Order yang tiba lebih dulu akan menjadi prioritas dalam produksinya.

Apabila ada order yang datang bersamaan maka order-order tersebut akan dikerjakan melalui antrian. Model penjadwalan seperti itu sering tidak menguntungkan bagi order yang membutuhkan waktu proses yang pendek karena apabila order tersebut berada di belakang antrian akan mengakibatkan waktu menganggur yang lama sebelum diproses di lantai pabrik. Sehingga berakibat besarnya total waktu penyelesaian seluruh pesanan (makespan) dilantai produksi, serta besarnya work in process di beberapa stasiun kerja. Makespan yang ada tidak dapat memenuhi batas waktu pekerjaan selesai (duedate). Apabila masalah tersebut tidak segera diatasi maka konsumen yang melakukan order akan kecewa dan melakukan komplain, bahkan perusahaan akan mendapat penalti karena keterlambatan pengiriman dan lambat laun akan kehilangan order yang menyebabkan perusahaan tidak mampu bersaing dalam dunia industri.

Penjadwalan didefinisikan sebagai rencana pengaturan kerja serta pengalokasian sumber baik waktu maupun fasilitas untuk setiap operasi yang harus diselesaikan [3]. Penjadwalan dapat diartikan sebagai proses pengalokasian sumber-sumber untuk memilih tugas dalam jangka waktu tertentu [4]. Definisi lain mengatakan bahwa penjadwalan ialah proses pengurutan pembuatan produk secara menyeluruh pada sejumlah mesin dalam jangka waktu tertentu [5].

Dari sekian banyak definisi penjadwalan yang telah ada pada saat ini, intinya adalah, penjadwalan berfungsi sebagai alat pengambilan keputusan, penjadwalan merupakan teori yang berisi prinsip-prinsip dasar, model, teknik, dan kesimpulan logis dalam pengambilan keputusan.

Beberapa tujuan yang ingin dicapai dengan dilaksanakannya penjadwalan produksi [6] adalah:Meningkatkan utilitas sumber daya atau mengurangi waktu tunggunya, sehingga total waktu proses dapat berkurang dan produktivitas dapat meningkat., mengurangi makespan, yang juga berarti menurunkan flow time rata-rata dan work in process rata-rata, mengurangi persediaan barang setengah jadi atau mengurangi sejumlah pekerjaan yang menunggu dalam antrian ketika sumber daya yang ada masih mengerjakan tugas yang lain. Teori Baker mengatakan, jika aliran kerja suatu jadwal konstan, maka antrian yang mengurangi rata-rata waktu alir akan mengurangi waktu persediaan, meminimasi biaya produksi, Mengurangi persediaan barang setengah jadi dengan jalan mengurangi jumlah rata-rata pekerjaan yang menungggu antrian suatu mesin yang dalam keadaan sibuk. Hal ini bertujuan untuk menghindari biaya flow time, yaitu biaya penyimpanan produksi setengah jadi, Memenuhi keinginan konsumen, baik itu dalam hal kualitas produk yang dihasilkan maupun dalam ketepatan waktu, Membantu dalam pengambilan keputusan mengenai perencanaan kapasitas pabrik dan jenis kapasitas yang dibutuhkan sehingga penambahan biaya yang mahal dapat dihindarkan. 


\section{Metodologi Penelitian}

Penelitian ini termasuk kedalam penelitian deskriptif (Deskriptive Research) yaitu suatu penelitian yang memaparkan masalah terhadap suatu masalah yang ada sekarang berdasarkan data secara sistematis. [7] Pada penelitian ini meliputi proses pengumpulan, penyajian dan pengolahan data serta analisa dan interpretasi.

Penelitian dilakukan pada PT. XYZ dilakukan selama 5 bulan. Jenis penelitian ini adalah penelitian deskriptif yaitu suatu jenis penelitian yang bertujuan untuk mendeskripsikan secara sistematik, faktual dan akurat tentang fakta-fakta dan sifat-sifat suatu objek atau populasi tertentu [8].

Variabel yang digunakan dalam penelitian ini, yaitu:

a. Urutan Penjadwalan

Variabel ini menunjukkan urutan pengerjaan order (job).

b. Makespan

Variabel ini menunjukkan total waktu penyelesaian seluruh job, yang dihitung berdasarkan selisih antara waktu stop job terakhir dengan waktu start job pertama, di mana urutannya dilihat dari satuan waktu.

c. Total Waktu Proses

Variabel ini menunjukkan banyaknya waktu yang dibutuhkan untuk menyelesaikan suatu pekerjaan sampai selesai yang hasilnya dipengaruhi oleh waktu standar, jumlah order, dan jumlah mesin, dimana ukurannya dilihat dari satuan waktu.

d. Waktu Standar

Variabel ini menunjukkan waktu yang dibutuhkan oleh seorang operator untuk menyelesaikan satu siklus kegiatan yang dilakukan menurut metode tertentu, pada kecepatan normal dengan mempertimbangkan faktorfaktor keletihan, kelonggaran untuk kepentingan pribadi. dimana ukurannya dilihat dari satuan waktu.

e. Tipe Produk

Variabel ini menunjukkan banyaknya jenis produk yang dihasilkan oleh pihak perusahaan

f. Jumlah Permintaan (Order)

Variabel ini menunjukkan banyaknya unit produk yang diminta oleh konsumen per periode dimana ukurannya dilihat dari satuan unit

g. Waktu Set Up

Waktu Set Up merupakan waktu yang digunakan untuk mempersiapkan mesin sebelum melakukan proses, agar mesin siap berproses.

Adapun tahapan pengolahan data pada penelitaian ini yaitu [9]:

1. Uji keseragaman

Selama melakukan pengukuran waktu kerja operator di tiap elemen kegiatan dimungkinkan mendapat data yang tidak seragam. Adapun alat yang digunakan mendeteksi ketidakseragaman data adalah peta kendali. Penelitian ini menggunakan tingkat kepercayaan $95 \%$ dan tingkat ketelitian $5 \%$. Uji keseragaman data dilakukan dengan menggunakan batas kontrol \pm 2 .

BKA $($ Batas Kendali Atas $)=$

BKB (Batas Kendali Bawah)

Data yang digunakan mewakili waktu kerja adalah data yang seragam.

2. Uji Kecukupan

Uji kecukupan data bertujuan agar data yang diperoleh melalui pengamatan yang dilakukan dapat mewakili populasi. Semakin banyak jumlah pengamatan maka hasil penelitian akan semakin mendekati kondisi yang sebenarnya. Dengan menetapkan tingkat keyakinan 95\% dan tingkat ketelitian 5\% maka formulasi yang digunakan adalah:

h. Jumlah Permintaan (Order)

Variabel ini menunjukkan banyaknya unit produk yang diminta oleh konsumen per periode dimana ukurannya dilihat dari satuan unit

i. Waktu Set Up

Waktu Set Up merupakan waktu yang digunakan untuk mempersiapkan mesin sebelum melakukan proses, agar mesin siap berproses. 
Adapun tahapan pengolahan data pada penelitaian ini yaitu:

3. Uji keseragaman

Selama melakukan pengukuran waktu kerja operator di tiap elemen kegiatan dimungkinkan mendapat data yang tidak seragam. Adapun alat yang digunakan mendeteksi ketidakseragaman data adalah peta kendali. Penelitian ini menggunakan tingkat kepercayaan $95 \%$ dan tingkat ketelitian $5 \%$. Uji keseragaman data dilakukan dengan menggunakan batas kontrol \pm 2 .

BKA $($ Batas Kendali Atas $)=$

$\operatorname{BKB}($ Batas Kendali Bawah) $=$

Data yang digunakan mewakili waktu kerja adalah data yang seragam.

4. Uji Kecukupan

Uji kecukupan data bertujuan agar data yang diperoleh melalui pengamatan yang dilakukan dapat mewakili populasi. Semakin banyak jumlah pengamatan maka hasil penelitian akan semakin mendekati kondisi yang sebenarnya. Dengan menetapkan tingkat keyakinan 95\% dan tingkat ketelitian 5\% maka formulasi yang digunakan adalah:

1. Menghitung waktu normal

2. Menghitung Waktu Baku (Waktu Standar)

3. Menghitung waktu penyelesaian

4. Menghitung Makespan dengan metode First Come First Serve(FCFS)

5. Menghitung Makespan dengan metode tabu search, perhitungan dibantu dengan menggunakan Ms Excel

6. Menghitung Number of tardy

Prosedur pengolahan data dapat dilihat pada Gambar 4.1 dan diuraikan sebagai berikut:

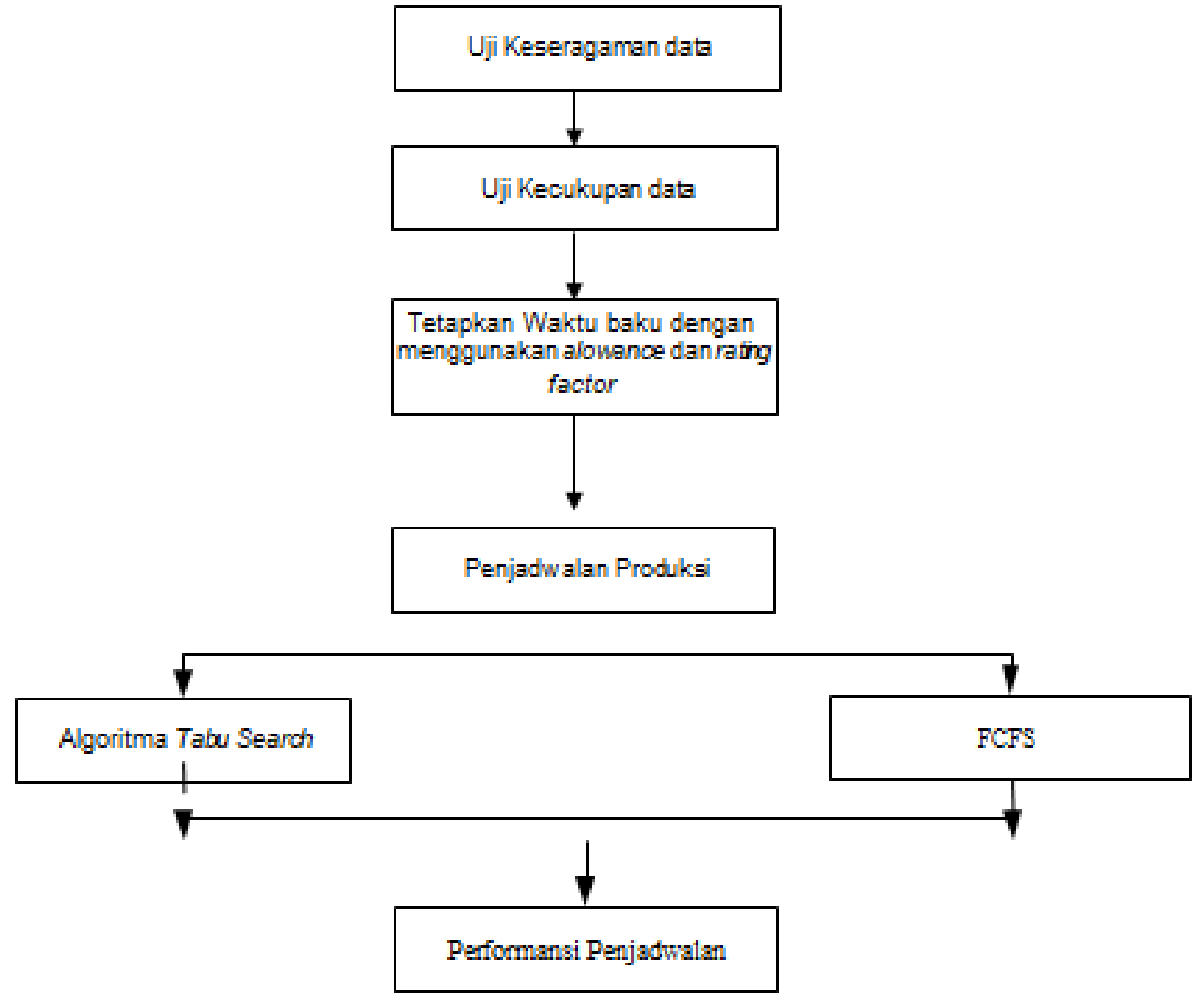

Gambar 1. Block Diagram Pengolahan Data 


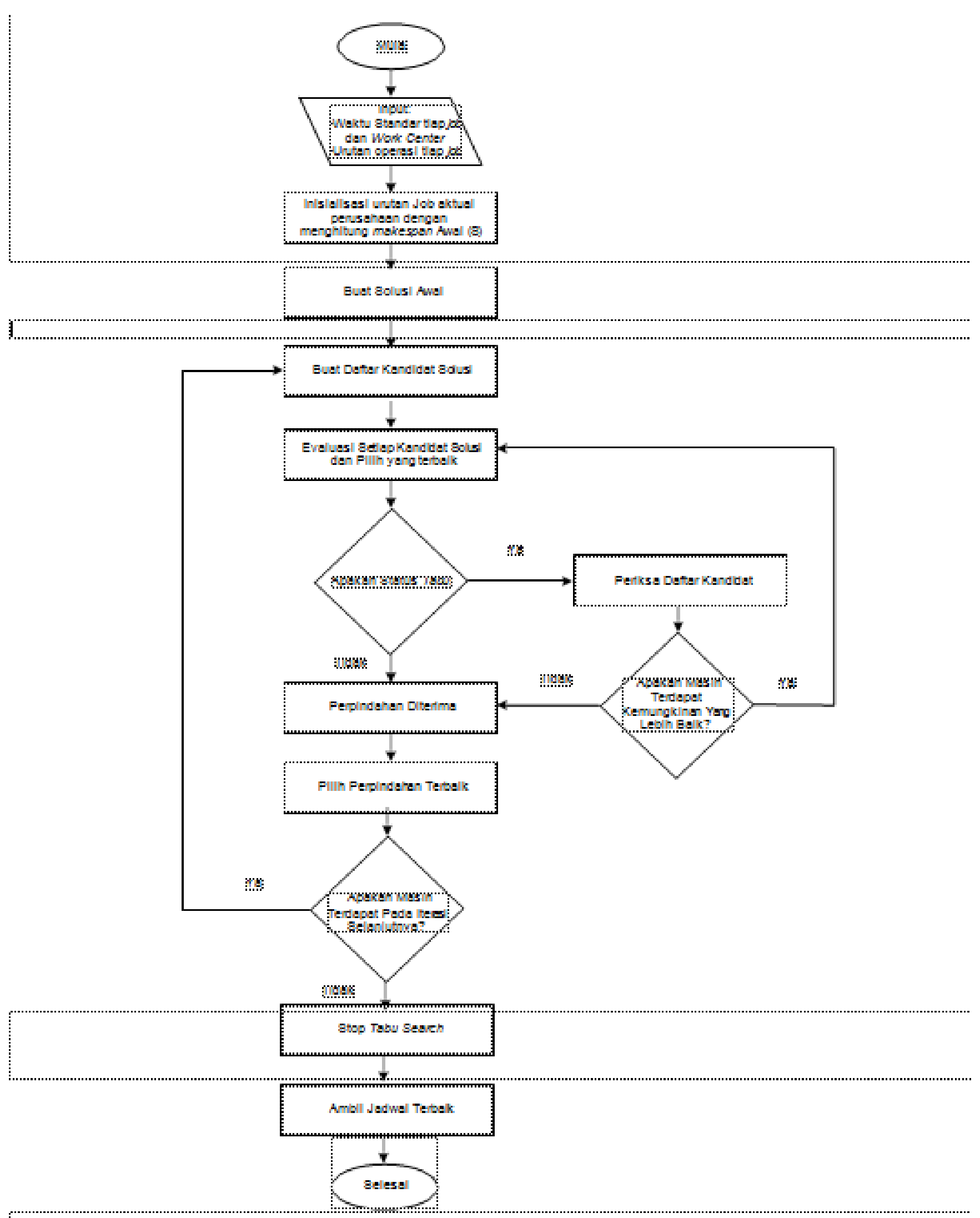

Gambar 2. Flowchart Algoritma Tabu Search 


\section{Hasil dan Pembahasan}

a. Analisis Penjadwalan dengan Metode First Come First Serve

PT. Jaya Beton Indonesia selama ini menggunakan metode First Come First Serve dalam menjadwalkan setiap job yang datang. Berdasarkan data yang diperoleh selama bulan Juli 2013 urutan job yang dikerjakan berdasarkan job yang pertama sekali datang adalah job 1- job 2- job 3- job 4- job 5- job 6- job 7- job 8 dengan makespan sebesar 815.6 jam

b. Analisis Penjadwalan dengan Algoritma Tabu Search

Hasil perhitungan dengan Algoritma Tabu Search diperoleh bahwa nilai makespan adalah 760.5 jam yaitu dengan urutan Job 1 - Job 4 - Job2 -Job 3 - Job 7- Job 6-Job 8- Job 5. Urutan ini diperoleh setelah dilakukan 5 kali iterasi.

c. Analisis Paramater Performansi Penjadwalan

d. Analisis Performansi dengan Efficiency Index (EI)

Untuk membandingkan antara metode yang diuji dengan metode yang digunakan oleh perusahaan maka dibandingkan berdasarkan parameter Efficiency Index (EI).

Efficiency Index $(\mathrm{EI})>1$, artinya metode tabu search memberi performance.

e. Analisis Performansi dengan Beda Relatif

Beda Relatif (RE) digunakan untuk mengetahui seberapa jauh perbedaan makespan yang dihasilkan oleh metode tabu search dan metode FCFS. Untuk nilai Beda Relative di atas menunjukkan bahwa perbedaan makespan yang diperoleh antara Algoritma Tabu Search dengan metode perusahaan adalah 7,24 \%. Hal ini menunjukkan Algoritma Tabu Search lebih baik dibandingkan metode perusahaan. Berdasarkan kedua parameter di atas, maka Algoritma Tabu Search lebih baik untuk menjadwalkan urutan pengerjaan di PT. XYZ yaitu dengan makespan $760.5 \mathrm{jam}$.

f. Analisis Kebaikan Metode Tabu Search

Metode tabu search menghasilkan makespan yang lebih pendek yaitu 55.1 jam atau 7,24\% lebih cepat dibandingkan dengan metode FCFS. Makespan yang lebih pendek tersebut dapat mengurangi waktu kosong pekerja dan memangkas biaya produksi. Waktu penyelesaian yang lebih cepat juga mengurangi keterlambatan dan kepuasan pelanggan terpenuhi serta komplain pelanggan menurun. Perusahaan dapat membangun kepercayaan konsumen dengan mudah dan besar kemungkinan terjadinya order berkelanjutan, kepercayaan konsumen dapat menjadi modal dalam bersaing dengan Kompetitor.

\section{Kesimpulan dan Saran}

Berdasarkan penelitian yang dilakukan di PT. XYZ dapat ditarik beberapa kesimpulan sebagai berikut:

1. Jadwal yang diperoleh dengan menggunakan Metode Algoritma Tabu Search adalah Job 1 - Job 4 - Job2 -Job 3 Job 7 - Job 6 -Job 8 - Job 5.

2. Metode penjadwalan produksi yang memberikan hasil yang optimum adalah Algoritma Tabu Search dengan menghasilkan total makespan sebesar 760.5 jam, Sedangkan makespan yang didapat dari metode penjadwalan aktual yang diterapkan di PT. Jaya Beton Indonesia dengan aturan First Come First Serve sebesar 815.6 jam.

3. Nilai Efficiency Index (EI) sebesar 1,0724 menunjukkan bahwa penjadwalan dengan Algoritma Tabu Search memiliki performance yang baik dibanding dengan metode First Come First Serve .

4. Nilai Beda Relatif (RE) menunjukkan bahwa penghematan makespan yang diperoleh antara Algoritma Tabu Search dengan metode perusahaan adalah $7,24 \%$.

1. Saran Bagi perusahaan

a. Agar perusahaan memeriksa ketersediaan kebutuhan pengadaan bahan baku, pengadaan operator.

b. Agar perusahaan dapat menerapkan suatu sistem database terintegrasi untuk memudahkan informasi ketersediaan material bahan baku, operator, dan pengoperasian mesin pada saat kegiatan produksi.

2. Untuk penelitian berikutnya

a. Agar dapat mengembangkan metode penjadwalan lain untuk menghasilkan hasil yang lebih baik dari metode 
yang telah diterapkan.

b. Sebaiknya penelitian ini dilanjutkan berdasarkan penyeimbangan lintasan produksi terlebih dahulu, sehingga ketidak seimbangan kapasitas antar stasiun kerja sudah mencapai titik mnimum.

c. Sebaiknya penelitian ini diterapkan sebagai alternatif pemecahan masalah dilapangan dengan terlebih dahulu menata ulang lantai produksi, sehingga stasiun kerjanya menjadi teratur dan tidak terjadi penumpukan barang setengah jadi pada tempat-tempat yang tidak semestinya

\section{Referensi}

[1] David D, Bedworth. 1987. Integreted Production Control System, Management Analysis, Design 2/E, Jhon Wiley, New York.

[2] Ginting, Rosnani. 2009. Penjadwalan Mesin. Yogyakarta : Graha Ilmu.

[3] Glover, Fred and Manuel Laguna.1997. Tabu Search. University of Colorado at Boulder. USA.

[4] Kusumadewi, Sri, Hari Purnomo. 2005. Penyelesaian Masalah Optimasi dengan Teknik-teknik Heuristik. Yogyakarta : Graha Ilmu.

[5] Michael C. Fu, dkk. 2000. Integrating Optimization and Simulation : Research and Practice. Proceeding of the 2000 Winter Simulation Conference.

[6] Michael C. Fu, dkk. 2002. Optimization for Simulation: Theory vs. Practice. INFORMS Journal on Computing 2002 vol 14, No.3, Summer 2002 pp. 192-215.

[7] Sumarjono, Wendi. 2013. Penjadwalan Produksi Pada Unit Produksi Pt X Dengan Menggunakan Algoritma Simulated Annealing Untuk Meminimasi Waktu Makespan. e-Jurnal Teknik Industri FT USU Vol 1, No.3, April 2013 pp. 8-10.

[8] Sutalaksana, Iftikar Z. 1979. Teknik Tata Cara Kerja. Bandung : Jurusan Teknik Institut Teknologi Bandung.

[9] Sritomo, Wignjosoebroto. 1998. Pengantar Teknik Industri. Surabaya: Guna Widya. 